\title{
A CIRCULAR CAUSATION MODEL OF THE OIL AND GAS SECTOR RELATIVE TO THE NON- OIL SECTOR IN THE SULTANATE OF OMAN
}

\author{
MASUDUL ALAM CHOUDHURY \\ Institute of Islamic Banking and Finance \\ International Islamic University Malaysia \\ SAEED AL-MUHARRAMI \\ College of Economics and Political Science \\ Sultan Qaboos University, Muscat, Sultanate of Oman \\ MOHAMMAD SALEH AHMED \\ Department of Mathematics and Statistics \\ Sultan Qaboos University, Muscat, Sultanate of Oman
}

\begin{abstract}
The goal of Omanization as a comprehensive focus of the productive and social transformation of the Omani economy with the retention of her domestic output and labour component in total national economic activity is studied by using the methodology of circular feedback between some critical macroeconomic variables that relate to oil and non-oil sectoral development. The existing scenario points out that the structural shape of inter-sectoral allocation of resources and their socio-economic results is based on marginal rates of substitutions. Contrarily, the development structure based on inter-sectoral and inter-variable causality leads to the suggestion of the complementary (participatory) development outlook. The emergent model of circular causation is used to study both cases; the 'as is' estimation case and the 'as it ought to be' simulation case in view of effective Omanization taken up in its broad definition of socio-economic sustainability. The simulation results that give rise to fresh directions on socio-economic structures and policy-making are further studied by the method of Spatial Domain Analysis of the GIS method.
\end{abstract}

Keywords: Economic development, development planning, sectoral planning, Oman development policies. 


\section{Background}

The Sultanate of Oman is poised to take off in its 2020-vision of accelerated growth and development by a selection of strategic and policy approaches. Of these approaches an important one is the diversification of the economy into the non-oil sector. The expectation of sectoral diversification in economic growth and development is high. In the region this emphasis is noted by a comparative examination of the results of non-oil sectoral diversification in Saudi Arabia, Oman's rich neighbour (Choudhury \& Sahlawi, 2000). Upon such a diversification programme these countries aim at interfacing development with higher employment, especially of Omanis, but not at the exclusion of non-Omanis who form a substantive proportion of the employed labour force in the private sector in Oman. This obviously means that the development process in the Sultanate of Oman is aimed at achieving its important wellbeing goal of increasing the Omani composition of productive employment but maintaining a fair balance of national and expatriate labour force between the public and private sectors, respectively. Towards achieving this goal there has to be significant education and training with human resource development expenditure in the target towards 2020. The sustainability of a complementary trend in the Oil/Gas and NonOil activities and employment as well marks the meaning of socioeconomic wellbeing, which will be evaluated.

\section{Objective}

The objective of this paper is to formalize an empirical model of circular causation as a method to study the complementarities between the critical development variables, while bringing out the methodological meaning of a socio-economic wellbeing model in the light of the interrelationship between the various critical factors of the Omanization goal as explained above. The meaning of Omanization is developed in reference to its wider sense of complementarities within the gamut of socio-economic goals of the Omani perspective on development sustainability and national wellbeing.

The paper is in three parts. Firstly, it part briefly examines the prevailing complementary relations between some key macroeconomic indicators for the Oil/Gas and Non-Oil sectors, and the state of employment distribution between nationals and expatriates. Secondly, the methodology of circular causation along 
with its analytical explanation is presented. Thirdly, the state of the Oman economy in the light of circular causation is explained. Fourthy, the empirical work is carried out with selected macroeconomic variables in the circular causation model of Oman's Oil and Gas sector relative to the Non-Oil sector. Finally, the analytical conclusion for policy-making on Omanization as a socio-economic wellbeing and development sustainability goal of the Sultanate of Oman is provided.

\section{The Goal of Omanization of Oman's National Economy}

The holistic goal of the national socio-economic wellbeing by creating, supporting, and sustaining a productive transformation of the economy within an increasing Omani perspective is the strategic goal referred to as Omanization of Oman's national economy. Omanization also means maintaining the complementary needs for achieving such goals between the Omani and the expatriate labour force. Thereby, the entire gamut of economic activity measured by productivity measures within the Omanization programme becomes a field of complementary activities between the Omani and the expatriate labour force. This means that sustainability of the Omanization programme in terms of economic and social goals of wellbeing must proceed without substantive replacement (or substitution) between Omani and non-Omani participation in Omani national development.

There are important theoretical constructs in such complementary perspectives of development within the Omanization strategy and oil/gas and non-oil sectoral diversifications of the economy. We will take up this study on a strategic perspective. Firstly, one needs to understand what diversification ought to mean for an economy whose sustainability depends upon the productive nature of the abundant resource, namely oil and gas. This brings us to a critical awareness of the sustainability objective upon which both the economic and social perspectives depend. Besides, the resilience of a critical awareness in the programme towards sectoral diversification into the non-oil sector that ought to be considered along the path of Omanization within the socio-economic development ought to be understood.

Table 1 brings out the state of Oman development over a long-time span. The importance of this trend is to show how the Oil and Gas sector has performed in proportion to total economic change. In the percentage shares of the GDP shown in Table 1 it is important to note the nominal trend which is above 50 per cent for the share of the non- 
oil sector in total GDP (total activity). During the same time period, the share of the Oil and Gas activity has declined marginally below 50 per cent of the total activity. Such a trend also means that in real and nominal terms the share values of the Oil and Gas sector declined compared to the Non-Oil and Gas sector. ${ }^{1}$ However, the absolute levels of the GDPs in current prices of these sectors increased; implying that nominal price levels of goods in these two sectors were contributing to the growth of revenue in the Oil and Gas sector, despite the somewhat declining trends in the GDP shares of the Oil and Gas sector. These trends show a trend towards complementarity between the Oil and Non-Oil sectors in the Omanization goal as a way of reaping the benefits of such complementarities in the total development of the Omani economy.

On the average, between the years 2000 and 2010, the Oil and Gas sector GDP grew approximately at an average annual rate of 28.23 per cent compared to the Non-Oil sector's average annual change of approximately 10.66 per cent during the same time period. This confirms the fact that the Oil and Gas sector was enjoying the nominal price effect of its goods in the growth of export revenue. This fact further affirms the effect of dynamic comparative advantage of the Oil and Gas sector in terms of conservation of output, while benefiting from the nominal price of Oil and Gas output in the international economy. International trade does matter in the development of the comparative sectoral output trends and thus its causality with a productive economic and social change. The comprehensive picture in the near complementary trends between the Oil and Non-Oil sectors contributing to the wellbeing indicators as the complementary use of the national and expatriate labour force feeds into the wellbeing aspect of the Omanization goal in the Sultanate of Oman.

Thus lastly in this paper, we invoke the educational expenditure variable that plays a significant role in the goal of Omanization in terms of the employment of the overwhelming young Omani population. Thereby, all the socio-economic variables ought to play their complementary roles in sustaining the comprehensive wellbeing objective of Omanization. Table 1 points out the trends of some critical variables between the years 2000 and 2010. The complementary change and sustainability argued here, are found to establish the potential path of the successful and comprehensive Omanization of Oman's national economy. 
IJMS 21 (2), 21-48 (2014)

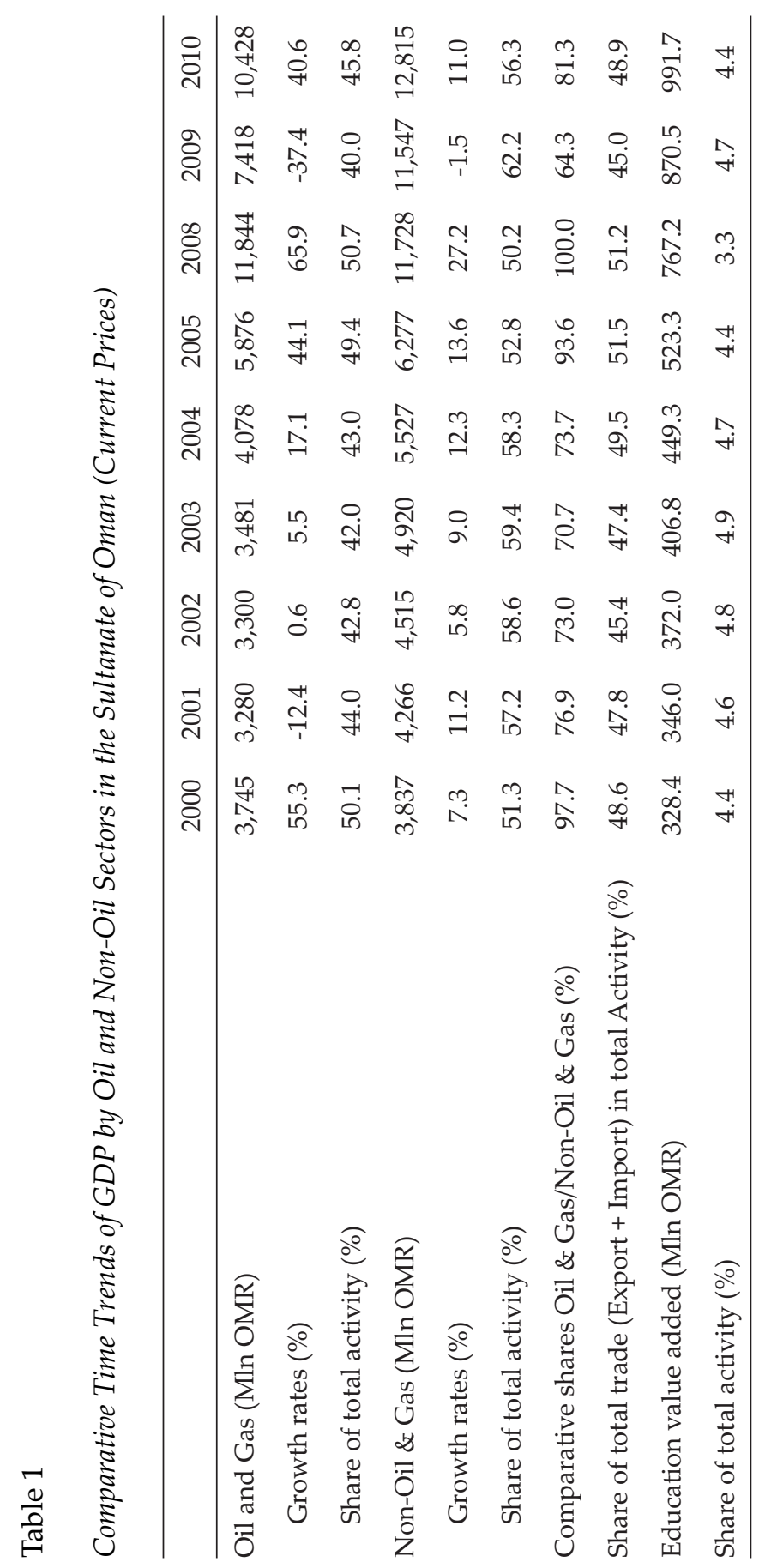


The inference to be drawn from the trends in the critical macroeconomic variables shown in Table 1 is that complementing the development of economic activities between the Oil and Gas sector and the NonOil sector results in the wellbeing objective both economically and socially. The effective diversification of the economy between oil and non-oil specializations in production as seen by the trends of their shares in total activity (GDP) would result in complementary gains of the Oil and Gas sector and the Non-Oil sector. The combined complementary effects of such diversification are expected to result in socio-economic wellbeing through educational enhancement along with the economic effects in an open economy. Such a comprehensive outlook of wellbeing explains the meaning of the goal of Omanization.

\section{The Prospect of Employment in the Comprehensive Omanization Goal}

An important goal of Oman's national development, and hence of Omanization, is to attain productive and sustainable employment within her comparative resource advantage. As mentioned above, such an employment prospect is desired for realization within the comprehensive socio-economic transformation. Besides, there ought to be also a balanced relationship between Omani employment and expatriate employment along the same direction of a complementary sectoral change with productivity, learning, diversification, and sustainability. Below we summarize such an employment perspective, and what can be expected in the contribution towards the Omanization of employment in its complementary, balanced and productively sustainable sense (Central Bank of Oman, 2013).

Given the demographic profile of Oman with a high proportion of young population, the focus of the Government has been to create more employment opportunities for the Omani youth joining the labour force. The Government embarked upon the Eighth Five-Year Development Plan (2011-2015) with the emphasis on education, training and creating employment opportunities for the youth, among others. As a result of the initiatives taken by the Government to create employment in the public sector, employment in the public sector in 2011 increased sharply by 12.5 per cent as compared to 2.8 per cent in the previous year. Of the total employment in the public sector, employment of Omanis stood at 86.3 per cent in 2011 as compared to 85.6 percent in 2010, indicating a steady progress of 
Omanization in terms of employment in the country. In 2012, private sector employment increased by 15.4 per cent compared to 13.7 per cent in the previous year.

Private sector employment is typically dominated by expatriates. Of the total employment in the private sector, expatriates accounted for 88.4 per cent in 2012 compared to 86.5 per cent in the previous year. Their large presence in this sector indicates a higher demand for such labour in a variety of activities. The construction sector continued to absorb the maximum number of expatriates with its share in the private sector employment rising to 44.3 per cent in 2012 compared to 43.4 per cent in the previous year.

The Government is taking several initiatives to improve the employment situation in the country by creating additional employment opportunities, emphasizing Omanization, increasing the minimum wage, improving the attractiveness of the private sector by streamlining public holidays in both the public and private sector, among others. The Government embarked upon the Eighth Five-Year Development Plan (2011-2015) with the emphasis on development of human resources. The Plan strives to widen the provision of employment through increasing investment, developing sectors of high labour-intensity, and developing small and medium enterprises which are employment intensive. The Plan emphasizes on improving the quality of education and training, which would ultimately lead to raising Omanization rates in various sectors of the economy. The Plan estimates to provide new employment in the range of 200,000 to 275,000 during the Plan (from 2011 to 2015), with an annual increase of around 40,000 to 55,000 employment opportunities.

Given the fair distribution of the national and expatriate employment between the public sector and the private sector the Eighth Development Plan is seen to move along the path of complementarity between these categories of the Omani labour force. Consequently, Omanization for the general wellbeing of the Omani economy and society is a sound development goal of the year 2020 .

\section{Oil and Gas Sector}

Sustained high crude oil prices in the global market and the increase in crude oil and gas production witnessed in Oman in 2012 further improved the contribution of this sector to the aggregate GDP. The average export price of the Omani crude oil increased by 6.5 per cent 
to US\$ 109.6 per barrel in 2012 from US\$ 103.0 per barrel in 2011. Oil production rose to a daily average of 918.5 thousand barrels in 2012 . On an aggregate basis, oil production rose by 4.1 per cent to 336.2 million barrels in 2012 from 323.0 million barrels in the previous year. Total oil exports rose by 3.9 per cent to 279.8 million barrels in 2012 from 269.4 million barrels in the previous year. Besides the production of natural gas registered an increase of 9.2 per cent to 37,919 million cubic meters during 2012 from 34,716 million cubic meters in the previous year. Natural gas was used for power generation, industries, industrial projects, as well as in various oil fields as fuel and for reinjection in oil wells to enhance production.

Other key macroeconomic indicators point to the continued dominance of the hydrocarbon sector in the Omani economy. Oil and gas revenues as a percentage of GDP stood at 40 per cent in 2012 and accounted for 85.4 per cent of government revenues and about 70 per cent of total merchandise exports (including re-exports) during the year. Major oil companies in Oman continued to invest in research and development for new technologies with the objectives of enhancing oil production from challenging geological formations and complex reservoirs as well as trying to minimize production costs. These companies initiated a number of new projects in 2012 in order to increase crude oil and gas production as well as to boost existing hydrocarbon reserves.

\section{Explaining Omanization as a Social and Economic Goal for Socio- Economic Wellbeing}

The above background on the economic and sustainable trends, and the Omanization perspective of Oman's national economy as noted, brings forth the important strategies that need to be studied. This focus will be the central objective of this paper as stated below. Among the principal strategies for Omanization in its comprehensive socioeconomic meaning is the sustaining of complementarities between the Oil and Gas sector and the Non-Oil sector, and thereby between the Omani employment and the expatriate employment, and between the public sector and the private sector, and sectoral balance and extensive complementarities between the critical variables in order to attain long-term economic sustainability and diversification. Such strategies can comprehensively lead to long-term sustained Omanization as a socio-economic wellbeing objective if driven by appropriate policies and adaptation along the complementary directions. 


\section{Wellbeing, Circular Causation, and Omanization}

What do these concepts mean at a technical level and how do they interrelate in explaining the comprehensive goal of Omanization? This topic is taken up first. A cursory examination of statistics, which will be subsequently followed by a detailed statistical analysis, indicates the following state of interrelations between some critical macroeconomic variables of Omani economy. This paper will study the inter-causal relations between the following critical variables (1) for empirical study. We will interrelate these inter-causal variables to study their interrelations in the framework of the endogenous growth theory:

$$
\begin{aligned}
& \mathrm{X}_{1} \text { : Comparative shares -- Oil \& Gas/Non-Oil \& Gas } \\
& \mathrm{X}_{2} \text { : Comparative growth rates Oil \& Gas/Non-Oil \& Gas }\{ \\
& \mathrm{X}_{3} \text { : Share of total trade (Export + Import) in total activity } \\
& \mathrm{X}_{4} \text { : Education value added Share of total activity }
\end{aligned}
$$

Despite the outlook on diversifying the economy from oil to nonoil specializations some critical factors ought to be kept in view in development planning. Dynamic comparative advantage in the sense of the endogenous growth theory (Romer, 1986), the impact of endogenous technological change, and human resource development with an open economy orientation of development planning in Oman to the year 2020 are important to note for sustaining long-run growth and wellbeing of the Omani economic and social landscape. The interface between the critical variables of socio-economic sustainability for Oman generates a complexity of synergistic interrelations that need to be identified, explained, and strategized. This is the nature of circular causation as a formal method to study pervasive endogeneity between inter-causal variables. Such extensively endogenous relationships manifest complementarities and the participatory nature of the social economy both by linkages between the sectoral variables and by choice of the endogenous policy variables.

For instance, the dynamic comparative advantage of the Oil and Gas sector in the Omani economic activities will necessarily imply preservation of such an endowment to interlink with the development of other sectors. Oil and gas revenue, which is found to enhance the GDP growth and its sectoral share of the Omani economy, needs to 
be sustained in a balanced way, rather than be allowed to fade away along the oil and non-oil substitution in economic change. ${ }^{2}$ On the other hand, the inter-sectoral linkages would also mean the support of the non-oil sectors through the development of oil-centered nonprimary industries. In the end, the complementarities caused and re-generated by the inter-sectoral linkages of such synergies of interrelations would result in a diversified participatory development process, in which an endogenous nature of causes and effects would work to sustain the emergent and continued form of preservation of resources, sharing of technology, networking in markets, and revenue coordination.

All these are taken up in the mix of the market economy with institutional change and government support. The role of the government will only be a parenting one. Diversification and sustainability of economic activities are regenerated by causes and effects of an emergent market economy well guided to maintain the inter-sectoral complementary balances in resource allocation for the development of such diversified sectors.

\section{A Brief Review of the Literature on Wellbeing and Circular Causation}

The endogenous cause and effect relationship by reflexivity between the complementing learning variables of diverse sectors is the underlying meaning of circular causation (Choudhury et al., 2011). The underlying cumulative experiences of social formation through such an interactive and integrative learning process have been studied in the literature mentioned here. Among these important factors are knowledge formation (Choudhury, 2009); complex technological effects (Bertuglia \& Vaio, 2005); X-efficiencies (Liebenstein, 1966) of conscious change, innovation, sustainability, and explanation of historical movement of cumulative social forces (Myrdal, 1958; Toner, 1999; North, 1981).

Yet the literature is lacking in the empirical viability of the concept of circular causation although writers in the area of social effects of complexity and change have studied this idea abundantly. On this fact writes Fitzpatrick (2003, p. 128): “Ours, then, is an age of simulations that endlessly refer only to other simulations. The infinite circularity of these self-references is what Braudrillard calls the simulacra: everything is a reproduction of other reproductions. Society explodes in on itself and we cannot liberate ourselves from the simulacra..." 
It is our understanding that the reason why an empirical version of the model explaining inter-causality by continuity of inter-variables, pervasively endogenous relations, could not be made, except in the limited case of Keynesian general equilibrium models, is due to the permanent presence of exogenous variables in such models. Thus policies become exogenous in such models. On the other hand, say in the case of the predominance of the privatization policy and government discursive relations with the private sector to participate in such a policy framework, the policy of privatization becomes endogenous. The endogenous result is due to the effect of discursive learning between inter-causal variables and entities, be these socioeconomic variables or polity (institution)-market interaction to generate integrative change along the discursive and participatory learning path.

A similar kind of methodology was invoked by Soros (2000) to explain his theory of reflexivity of entity relations in the stock market. Following Popper's (1972) dialectical ideas, Soros explained the theory of reflexivity in history. The reflexivity theory is a simple explanation of the following fact: The probabilistic outcome of any decision is an event with all different prospects including levels of success and failure. But any such event gives rise to a recursive probabilistic realization of the next stage of decision-making in the same or contiguous game. Simulation thus becomes a repetitive process of successive decisions and prospects in the form of circular causation.

Participatory development is studied as a system study in complex patterns of causes and effects carried through by sequentially interrelated nodes of decision-making with inter-causal variables (Jackson \& Kassam, 1998; Shakun, 1988). In spite of such modelling, the emergent system models become increasingly difficult to simulate, even with highly powerful smart computers. This is because of the immensity of circular loops that are generated by the continuity of simulation via circular causation relations across various systems.

Circular causation of the type of complementarities in decisionmaking was studied by Simon (1957) in his theory of satisfying behaviour of organizations. Yet one notes that the dynamics of satisficing simulacra are broken by constraining continuous forms of perturbations in decision-making within bounded rationality. Within bounded rationality the postulates of rational economic choice reappears. Such limits of rational decision-making can be extended by 
exogenous technological change. Endogenous technological change and behavioural change are not part of Simon's evolutionary model of satisfying behaviour of the firm (Simon, 1960).

In the case of Oman, a development planning model was completed by Choudhury and Hossain (2006) to study the inter-sectoral linkages by a circular causation model between the variables - GDP, investments, employment, and human resource development. The results of the circular causation model were then carried over to set up a matrix model of such inter-sectoral linkages. Finally, the innovative method of Spatial Domain Analysis was applied to display the topography of such sectoral linkages and simulate the coefficients of the multiple structural equation system of circular causation. Policy analysis was then carried out of the empirical results to suggest a more robust form of sectoral linkages under the mandate of the Sixth Development Plan of the Sultanate of Oman.

In the end we note that, the circular causation phenomenon and its modelling as a permanently evolutionary learning method of simulation of continuous relations can explain the systems of causality between variables. Such paths of interrelated variables are caused and regenerated by the feedback of the induction of knowledge and technology, widely defined to give rise to interactive complementarities between the systems of variables. The result of such complementary relations is endogenous learning by the evolution intra-system and the inter-system.

A truncation of such evolutionary learning paths of processes is by the needs of the problem under study. The end of one process is taken over by another in continuity, intra-system as well as inter-system. There remains a methodological property of circular causation models inherent in the continuously evolutionary learning paths of diversity of inter-variable relations.

\section{Circular Causation and Wellbeing}

The wellbeing objective function is defined by the pervasiveness of complementarities between the requisite variables of a participatory socio-economic development. Such complementarity inter-variables may not exist, may be negative, can be weak, medium or strong in any development process. Negative and weak levels of complementarities are improved to generate better levels of simulated wellbeing out of the circular causation results. Complementarities also signify 
endogenously evolutionary learning properties of the multivariate interacting, integrating, and evolutionary systems. Consequently, all of the following properties of the wellbeing model are coterminous: Participation (complementarities), endogenous nature of evolutionary relations, discursive patterns of inter-entity learning, and simulacra property of circular causation relations spanning over complexity but simplifying it for empirical and predictive purposes. A complete anomie of complex systems (Taleb, 2007) is avoided by the inherent methodology of the generalized system of wellbeing simulation subject to circular causation to generate both the existing (as is) and the normative (as it ought to be) simulated future of complementary relations by degrees as required.

\section{The Formal Model of Wellbeing Simulation Subject to Circular Causation Relations}

Let the wellbeing simulation function given its properties as above be denoted by,

$$
\operatorname{Sim}(q) \cdot W(q)=\operatorname{Sim}(q) \cdot W(q, x(q))
$$

As in an earlier footnote, $\mathrm{q}$ denotes inducing knowledge that endogenously regenerates

complementary reproducible linkages between the elements of $\mathbf{x}(\mathrm{q})$-vector.

Simulation (1) is performed subject to the circular causation system of equations,

$$
\begin{aligned}
& x_{i}=f_{i}\left(q, x_{j}(q)\right),(i, j)=1,2, . ., n ; i^{1} j \text { with, } x(q)=\{x 1(q), x 2 \\
& (q), \ldots, x n(q)\}
\end{aligned}
$$

yielding finally the 'measured wellbeing index' (explained below),

$$
\mathrm{q}=\mathrm{F}(\mathbf{x}(\mathrm{q}))
$$

Note that equations (1) and (4) are 'similar' functions. We refer to expression (1) as the conceptual framework of the wellbeing criterion. But by itself this function is not empirically viable because there are no available data values of $\mathrm{W}(\mathrm{q})$ to perform estimation in terms of the $\mathbf{x}(\mathrm{q})$-variables. On the other hand, equation (4) is empirically viable for estimation with ordinal values of ' $q$ '. 
q-values are generated in the following way: An arbitrary rank, say of 10 (but not restricted to this value), is assigned to the best $x_{i}(q)-$ value in specific columns of such values and according to relevance in the problem under study. The rest of the $\mathbf{x}(\mathrm{q})$-values are used to prorate the respective q-values. The ranked q-values so generated by each column are then averaged across the columns to generate the final q-values. These are used for estimating equations (1)-(4). Such an evaluation exercise by virtue of the estimated coefficients denotes the 'as is' state of the problem under study. We refer to this phase of empirical evaluation of the system (1)-(4) as the 'estimated' phase.

The 'estimated phase' is next 'simulated' by the desired values of the coefficients according to the possible impact of factors like endogeneity of technology, policies and resources, and strategic discourse. These factors characterize the evolutionary learning process in simulation. In such ways, the simulated estimators are generated by the system of structural equations,

$$
\begin{aligned}
& x_{i}^{\wedge}=f_{i}^{\wedge}\left(q, x_{j}(q)\right), \\
& (i, j)=1,2, . ., n ; i^{1} j \text { with, } x^{\wedge}(q)=\left\{x_{1}^{\wedge}(q), x_{2}^{\wedge}(q), \ldots, x_{n}^{\wedge}(q)\right\} \\
& q^{\wedge}=F\left(x^{\wedge}(q)\right)
\end{aligned}
$$

The simulated system (5)-(7) can be further simulated by processes of simulacra as mentioned earlier. Such simulacra represent continuously changing coefficients according to the endogenous effects towards establishing new phases of complementarities between the socio-economic variables arising from conscious choices of technology, policies, and structural change - all acquired out of consensus by discourse. One method for displaying such simulacra of choices of coefficients is the Spatial Domain Analysis. This method is represented in the simulation results shown in the Technical Appendixes of this paper.

The meaning of pervasively endogenous variables and their inter-causal relations is established on the basis of the strong role that choices made by consciousness, discourse, and observed interrelations altogether play in heightening the systemic power. Thereby exogenous relations are replaced by endogenous relations as the systemic unity (complementarities) of interrelations between the variables and systems increase. In development planning such interrelations denote sectoral linkages, and the heightening role of markets, systems, and evolutionary learning processes. 


\section{Empirical Work for the Omanization Goal of Participatory Oil and Non-oil Development}

The following data set is used to run the circular causation system of equations. Also given is the reason for adopting this system. The statistical results are analysed and explained. The simulation of the circular causation system in the light of the 'measured wellbeing' index is displayed by the use of the SDA method of GIS. These results are shown in the Technical Appendix. The data set comes from Table 1.

The form of the estimated models and the explanation of the results of circular causation are given below. The variables chosen to study circular causation and the effect of the inter-variable causality in the wellbeing function are $x(q)=\left\{x_{1}, x_{2}, x_{3}, x_{4}\right)[q]$ to examine complementarities between the variables that would be signified by the common effect of the q-value on the variables shown.

\section{Empirical Work}

Such expected inter-variable complementarities, if they exist, are explained by the fact that, the balance of inter-sectoral participation in development would require simultaneous balanced trends in the relative share-ratio and growth rate of the oil and non-oil sectors. Such a comparative trend would imply the degree of openness of the Omani to international trade. This would imply inter-causality between export and import. Openness in turn will relate to productive activity as mentioned above via inter-causality between all such variables. The connecting variables to maintain such inter-variable circular causality are competitive prices of oil and non-oil categories of goods. The export revenue so raised would generate a positive effect on educational expenditure to raise Omani productivity in the labour force, and thereby, in the two sectors. Likewise, heightened educational components of inter-sectoral productivities would be enhanced circularly by the emergence of Omani retention of goods and services. It is a phenomenon known as In-Country Valuation (Tordo et al., 2013).

Such inter-variable complementarities by circular causal relations define the comprehensive meaning of Omanization as a national goal of wellbeing. The comprehensive wellbeing model of Omanization in our macroeconomic study on a limited scale will be explained by the evaluation of the following model: 
Evaluate the following circular causation equations in their given structural form:

$$
\begin{aligned}
& \mathrm{x}_{1}=\mathrm{a}_{0}+\mathrm{S}_{\mathrm{i}=2}^{4}{ }^{4} \mathrm{a}_{\mathrm{i}} \cdot \mathrm{x}_{\mathrm{i}} \text {, leaving out } \mathrm{x}_{1} \\
& \mathrm{x}_{2}=\mathrm{b}_{0}+\mathrm{S}_{\mathrm{i}=1}^{4}{ }_{\mathrm{i}} \cdot \mathrm{b}_{\mathrm{i}} \text {, leaving out } \mathrm{x}_{2} \\
& \mathrm{x}_{3}=\mathrm{c}_{0}+\mathrm{S}_{\mathrm{i}=1}^{4}{ }^{4} \mathrm{c}_{\mathrm{i}} \cdot \mathrm{x}_{\mathrm{i}} \text {, leaving out } \mathrm{x}_{3} \\
& \mathrm{x}_{4}=\mathrm{d}_{0}+\mathrm{S}_{\mathrm{i}=1}^{3}{ }_{\mathrm{i}} \cdot \mathrm{x}_{\mathrm{i}} \text {, leaving out } \mathrm{x}_{4}
\end{aligned}
$$

The simplified form of the wellbeing function we will take is generated as follows:

$$
\mathrm{q}_{\mathrm{i}}=\mathrm{S}_{\mathrm{j}=1}{ }^{4} \mathrm{x}_{\mathrm{ij}} \text { by rows }
$$

The overall 'measured wellbeing' is the average of the estimated q-values connected with the degree of complementarities or absence of it or weakness. This measure is shown by the simple average in expression (13). ${ }^{3}$ More elaborate forms of such functions can be chosen. Thus the average measured wellbeing value is given by,

$$
\mathrm{F}=\mathrm{S}_{\mathrm{i}=1}^{\mathrm{n}}{ }^{\mathrm{n}}\left(\mathrm{q}_{\mathrm{i}} / \text { \# } \text { observations }\right) \text {. }
$$

\section{‘Estimation’ Results}

The variables $\left\{\mathrm{X}_{\mathrm{i}}\right\}, \mathrm{i}=1,2,3,4$ were defined earlier in expression (1).

$$
\begin{aligned}
& \text { (1) } \hat{X}_{1}=0.88-0.00196 X_{2}+1.08 X_{3}-13.1 X_{4} \\
& \text { R-square }=84.1 \% ; \mathrm{DW}=0.878631, \mathrm{P} \text {-Value }=0.019^{*}
\end{aligned}
$$

Relative shares for (Oil \& Gas/Non-Oil), and the corresponding relative growth rates for (Oil \& Gas/Non-Oil) are marginal substitutes of one another. Complementarity between these variables does not exist. This means that even as the relative growth rates of output increase (or decrease), the shares decrease (or increase) to maintain the balance of price-competitiveness of either the Oil \& Gas Sector or the Non-Oil Sector, respectively, as the case may be. Such a marginal rate of substitution is not welcome in view of sustainability of both the sectors to maintain the dynamic comparative advantage of both sectors in a balanced development of the Omani economy. 
The Oil \& Gas relative shares increase (or decrease) in tandem with the increase or (decrease) in this sector's openness to international trade. In such sectoral penetration into international trade, the Oil \& Gas sector has an advantage over the Non-Oil sector along with the price-competitiveness of the Oil \& Gas sector in international trade. The openness to international trade implies that Oil \& Gas sector holds good terms of trade and comparative advantage compared to the Non-Oil sector. Such effects are shown from the side of the relative growth rate affecting relative shares in estimated equation (14).

But even with the good results on the side of the Oil \& Gas sector compared to the Non-Oil sector for Oman in respect of pricecompetitiveness (good terms of trade) and openness of the Oil \& Gas sector in international trade, the impact of such gains is not helping in enhancing educational expenditure growth for the benefit of the Omanization of labour. By our earlier definition of Omanization as the comprehensive goal of productive transformation of the economy, sustainability, and human resource development for productive employment in the Omani socio-economic scenario, the statistical result suggests that, a more aggressive role ought to be launched to attain a better balance between the Oil \& Gas sector and the NonOil sector.

$$
\begin{aligned}
& \text { (2) } X_{2}=176-31.9 X_{1}-218 X_{3}-891 X_{4} \\
& \text { R-square }=32.9 \% ; D W=2.15221, \text { P-Value }=0.537
\end{aligned}
$$

A similar result is found to exist on the side of the relative shares ratios affecting the relative growth rates, that is, even though the Oil \& Gas sector substitutes its relative shares for relative growth rates in total economic activity, the movement of these variables opposite to each other, would not strengthen the international trade status of the Oil \& Gas sector unless the relative shares and growth increase together to generate the price competitiveness to fuel the development of both these sectors in a complementary fashion and take the benefit of the price-competitiveness in international trade. The explanation for the price-competitiveness effect of relative growth on relative shares for Oil \& Gas that we found in equation (14) is not found to be sustained by the reverse causality between these variables.

Thereby, the substitution of relative shares for growth relative has a diminished effect, as in the case of the substitution of the growth relative to relative shares in the international trade competitiveness 
of Omani Oil \& Gas. An explanation of this result is that, an increase in growth relative over relative shares means so much that it should enter international trade as export. On the other hand, an increase in shares if not complementary to the growth relative, intensifies the use of Oil \& Gas domestically and reduces trade penetration. Openness is then adversely affected in this case.

Finally, we note that according to the causality between the variables shown in equation (16), the impact of educational expenditure does not contribute to the growth relative. That is educational expenditure is not generating sufficient productivity to sustain the complementarity needed between $X_{1^{\prime}} X_{2^{\prime}}$ and $X_{3}$. The Omanization programme is shown to be adversely affected by such a development scenario. This is therefore, a matter for simulating the individual coefficients to generate better sustainable inter-variable productive simulations to attain a better scenario of Omanization.

$$
\begin{aligned}
& \text { (3) } X_{3}=0.484+0.066 X_{1}-0.000824 X_{2}-1.14 X_{4} \\
& \text { R-square }=68.5 \% ; D W=1.37983, P \text {-Value }=0.100
\end{aligned}
$$

The results further reinforce that, unless relative shares $\left(X_{1}\right)$ and growth relatives $\left(X_{2}\right)$ for the Oil \& Gas sector are complementary, $X_{2}$ is found to substitute for share of trade in total economic activity. The present state of the desired effectiveness of educational expenditure is not found to generate the contribution of a productive labour force to impact on trade, which otherwise can be caused by the complementarities between $X_{1}$ and $X_{2}$. The comprehensive objective of Omanization is adversely affected.

$$
\begin{aligned}
& \text { (4) } \mathrm{X}_{4}=0.113-0.0449 \mathrm{X}_{1}-0.000188 \mathrm{X}_{2}-0.064 \mathrm{X}_{3} \\
& \text { R-square }=82.9 \% ; \mathrm{DW}=1.51559, \mathrm{P} \text {-Value }=0.020^{*}
\end{aligned}
$$

Because of the loss of the complementarities between $X_{1^{\prime}} X_{2^{\prime}} X_{3}$ that are thereby found to adversely affect the comprehensive Omanization programme, such an overwhelming scenario of development based on marginal rates of substitution is found not to result in productive levels of educational expenditure.

Finally, the level of measured wellbeing calculated by equation (13) gives the value,

$$
\mathrm{F}=6.10
$$


The variance of the observations is 16.68 . The inference then is that the wellbeing value of 6.10 is not representative of the randomness of the sample. The value of the measured wellbeing indicates that there is unrealized potential for effective Omanization that can come about by restructuring the economy with development planning and policies in the direction of the complementary effects between the variables $\left(X_{1}, X_{2}, X_{3}, X_{4}\right)$. The value of the variance and standard error of estimates would then reduce substantially. We have brought out possible cases of simulation of the coefficients of the estimated equations in the charted results of the SDA in the Technical Appendix.

\section{The SDA Results of Simulation of Estimated Coefficients}

In order to realize better complementarities between the variables to gain on the Omanization goal, the estimated equations are to be simulated by changes in the coefficients for complementarities between the variables. While this is an elaborate empirical undertaking, it is only indicative here. By the results of circular causation, the SDA method is used to generate a generalized topography of simulations in the Technical Appendix. The following forms of the simulation equations are examined for more complementary results to yield better levels of wellbeing for the case of Omanization:

$$
\begin{aligned}
& \mathrm{X}_{1}=\mathrm{a}_{0}+\sum_{\mathrm{i}=2}{ }^{4} \mathrm{a}_{i} . \mathrm{X}_{\mathrm{i}} \text {, leaving out } \mathrm{x}_{1} \\
& \mathrm{x}_{2}=\mathrm{b}_{0}+\sum_{\mathrm{i}=1}{ }^{4} \mathrm{~b}_{\mathrm{i}} . \mathrm{x}_{\mathrm{i}} \text {, leaving out } \mathrm{x}_{2} \\
& \mathrm{X}_{3}=\mathrm{C}_{0}+\sum_{\mathrm{i}=1}{ }^{4} \mathrm{C}_{1} . \mathrm{X}_{\mathrm{i}} \text {, leaving out } \mathrm{x}_{3} \\
& \mathrm{x}_{4}=\mathrm{d}_{0}+\sum_{\mathrm{i}=1}{ }^{3} \mathrm{~d}_{\mathrm{i}} . \mathrm{x}_{\mathrm{i}}, \text { leaving out } \mathrm{x}_{4}
\end{aligned}
$$

The choice of the simulated selection of coefficients in expressions (18)-(21) can be made from the SDA generated list of 'estimated' coefficients in expressions (14)-(17). See the example of such generating of coefficients by the side of the SDA maps in the Technical Appendix. Yet the mere selection from the generated numbers by their relative coloured contours is not enough. The selected coefficients are subject to discussion before accepting them.

As an example, and the rest of the results can be similarly interpreted, equation (18) implies the following results: (a) A unit percentage change in $X_{2}$ ceteris paribus will cause an increase of $0.00196^{*}\left(X_{2} / X_{1}\right)$ per cent change in $X_{1}$ ceteris paribus, (b) a unit percentage change in $X_{3}$ 
ceteris paribus will cause an increase of $1.08^{*}\left(X_{3} / X_{1}\right)$ percentage change in $X_{1}$ for given values of $\left(X_{1}, X_{3}\right)$ and (c) a unit percentage change in $X_{4}$ ceteris paribus will cause an increase of $5.1^{*}\left(X_{4} / X_{1}\right)$ percentage change in $X_{1}$ for given values of $\left(X_{1}, X_{4}\right)$. Each of such computed values represent partial (ceteris paribus) elasticity coefficients of $X_{1}$ to the other variables, respectively.

With the illustrative simulation equation (18) the SDA results convey the following scenario. The other SDA results can be similarly interpreted; equation (18) demonstrates that there is strong correlation or interaction between $X_{1}$ and $X_{4}$. This interaction is shown in Figure 1 by using a dark color. In addition, a lower interaction between variables $X_{1}$ and $X_{2}$ can be observed from equation (18). This phenomenon of lower interaction is demonstrated in Figure 1 with a very light color. The important difference between the regression equation (as demonstrated in equation (18) and the SDA (Spatial Domain Analysis) approach is that in the regression approach at a point in space the interaction between two variables (say, for example, $X_{1}$ and $X_{4}$ or $X_{1}$ and $X_{2}$ or $X_{1}$ and $X_{3}$ ) can be calculated.

The additional benefit of the SDA contours is to observe the simultaneous degrees of complementarities between all the variables together, unlike the partial results of the regression equations. This versatility of the SDA results is shown for the different equations according to their charts in the Technical Appendix.

\section{Conclusion}

The study of the interrelationships between some critical macroeconomic variables in the light of the goal of Omanization taken up in its comprehensive sense of inter-sectoral complementarities, and thus sustainability of economic and social relations for the Sultanate of Oman, points out that there remain gaps that ought to be filled up for moving into this target by the year 2020 as the grand development planning focus. The Non-Oil sectoral development need not be substituted for the Oil \& Gas sector. The sectors need to continue to be complementary.

Our study here shows that, the feedback between these sectors in terms of some critical ratios of development defining domestic forces and those representing the penetration into international trade is 
holding up the path of complementarities between the Oil/Gas and Non-Oil economic sectors and the national and expatriate labour forces in the public and private sectors, respectively.

In the end, it is statistically noted that, any pursuit of the substitution case between the Oil \& Gas and Non-Oil sectors ought not be pursued. Otherwise the socio-economic trends will adversely affect the educational expenditure on Omani employment in attaining the Omanization goals of a sustainable economic and social change within the socio-economic development planning. Likewise, the effects of educational expenditure in enhancing human resource development will adversely affect the development of sectoral complementarities with sectoral diversification.

Circular causation equations that bring out the nature of the existing interrelations between the inter-causal variables have shown in this paper that there are overall marginal rates of substitution rather than complementarities between the selected variables. Thereby, comprehensively productive Omanization as a development and wellbeing goal needs structural and strategic attention.

The results of simulation of the estimated results generating the complementary scenario in development as a possibility with policies and In-Country Valuation for Oman can engender the much aspired-for goal of socio-economic wellbeing by the productive and sustainable Omanization effects. Such results are shown by the SDA topography as examples.

The following are the definitions for the variables; $\mathrm{x}_{1}$ : Comparative shares Share of total activity Oil \& Gas/Non-Oil \& Gas; $\mathrm{x}_{2}$ : Comparative growth rates; x3: Share of total trade (Export + Import) in total activity; $\mathrm{x}_{4}$ : Education value added $\left(\mathrm{x}_{4}\right)$.

The variables chosen to study circular causation and the effect of the inter-variable causality in the socio-economic wellbeing function are $x(q)=\left\{x_{1}, x_{2}, x_{3}, x_{4}\right)[q]$ to examine the complementarities between the variables that would be signified by the common effect of q-value that causes a technological-type induction of the $\mathbf{x}(\mathrm{q})$-interrelations to generate their desired complementarities. 
IJMS 21 (2), 21-48 (2014)

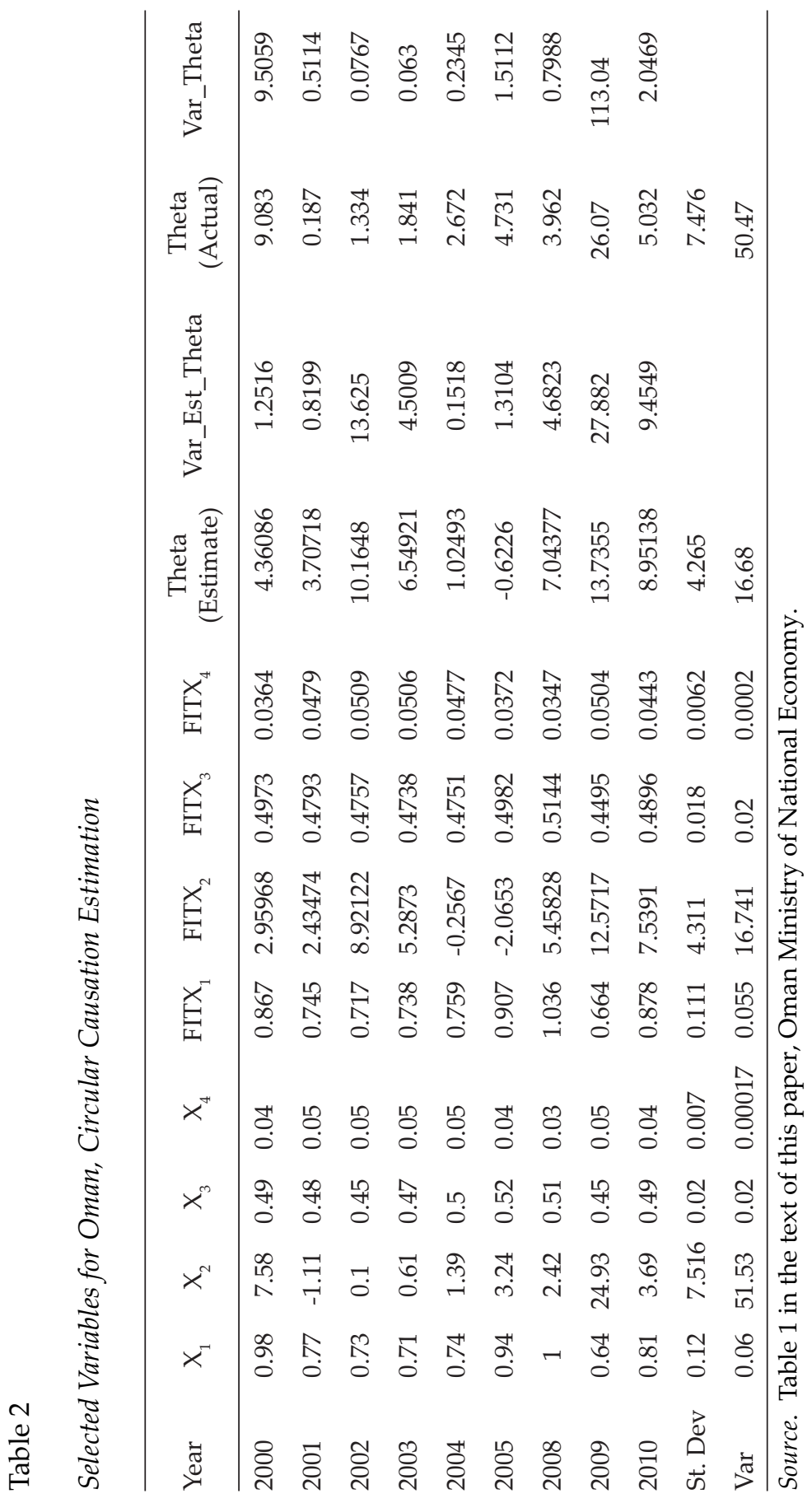


Such expected inter-variable complementarities are explained by the fact that the balance of inter-sectoral participation in development would require simultaneous balanced trends in the relative shareratios and growth rate of the oil and non-oil sectors. Such a comparative trend would imply openness of the Omani in international trade. This would imply inter-causality between export and import. Openness in turn will relate to productive activity as mentioned above via intercausality between all such variables. The connecting variables to maintain such inter-variable circular causality are competitive prices of oil and non-oil kinds of goods. The export revenue so raised would generate a positive effect on education expenditure to raise Omani productivity in the labour force. Likewise, heightened educational components of inter-sectoral productivities would be enhanced circularly by the emergence of Omani retention of goods and services. It is a phenomenon known as In-Country Valuation (Tordo et al., 2013).

Such inter-variable complementarities by circular causal relations define the comprehensive meaning of Omanization as a national goal of socio-economic wellbeing. The comprehensive wellbeing model of Omanization in our macroeconomic study on a limited scale will be explained by the evaluation of the circular causation model. This is done by the Spatial Domain maps shown in Technical Appendix 2.

\section{Technical Appendix 2: Spatial Domain Analysis Results}

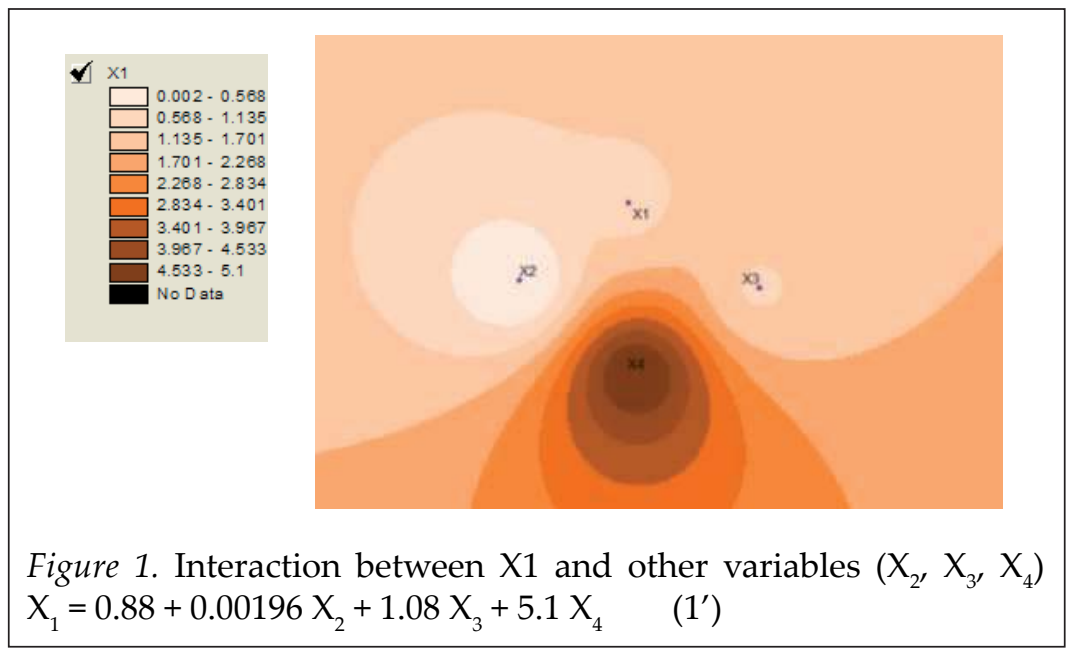


IJMS 21 (2), 21-48 (2014)

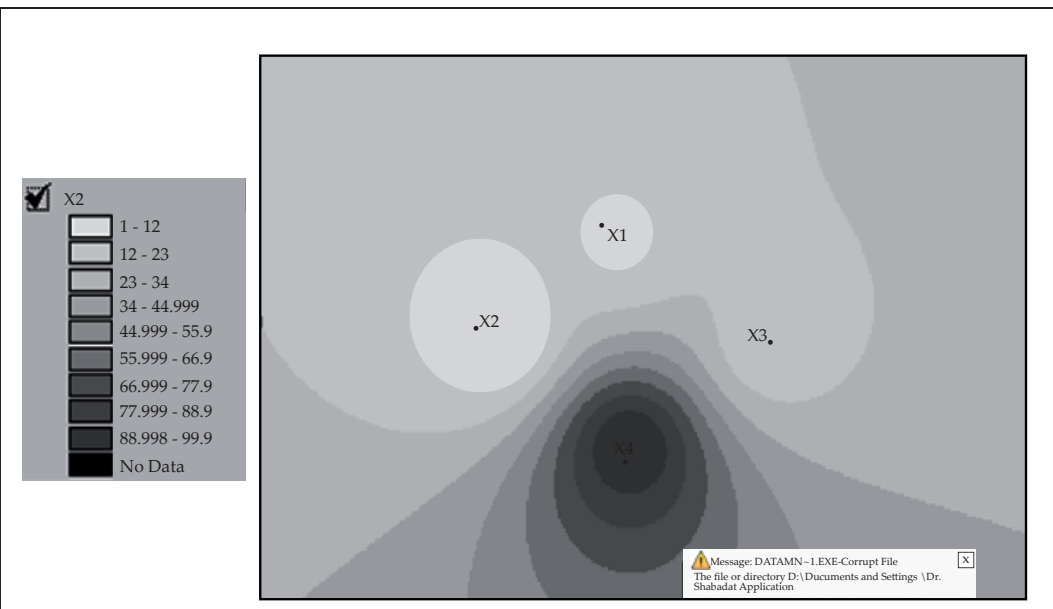

Figure 2. Interaction between $X_{2}$ and other variables $\left(X_{1}, X_{3^{\prime}}, X_{4}\right)$. $X_{2}=76+10.0 X_{1}+15.0 X_{3}+100 X_{4}$

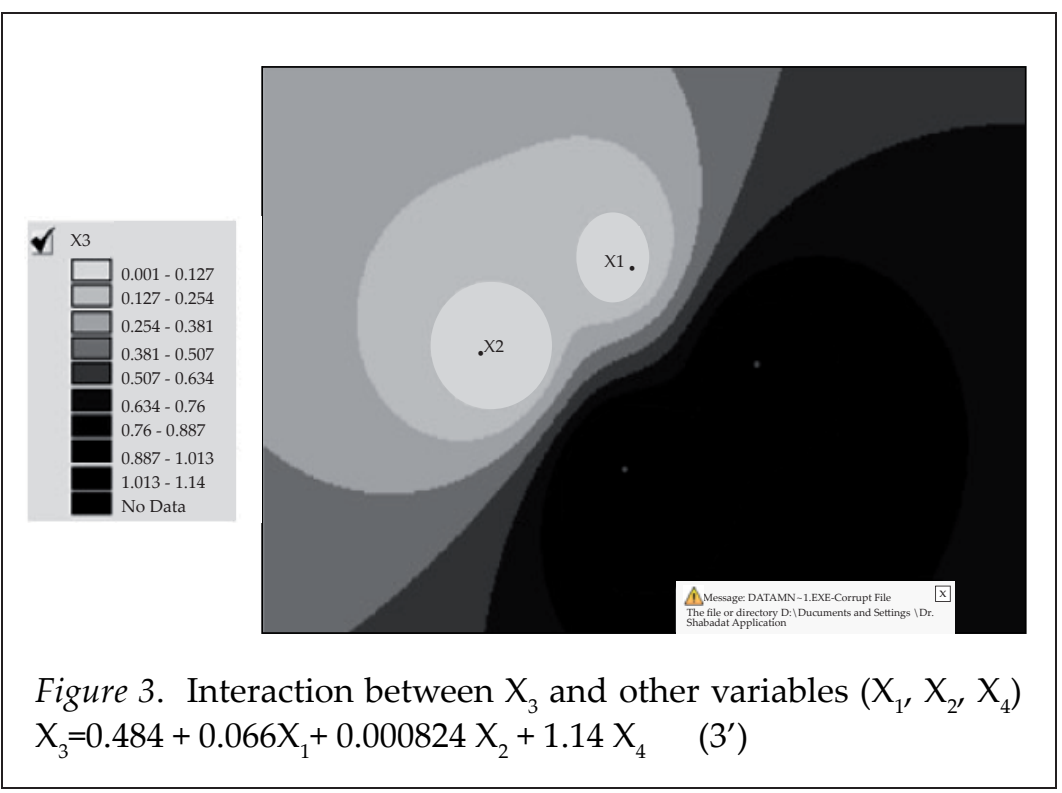


IJMS 21 (2), 21-48 (2014)

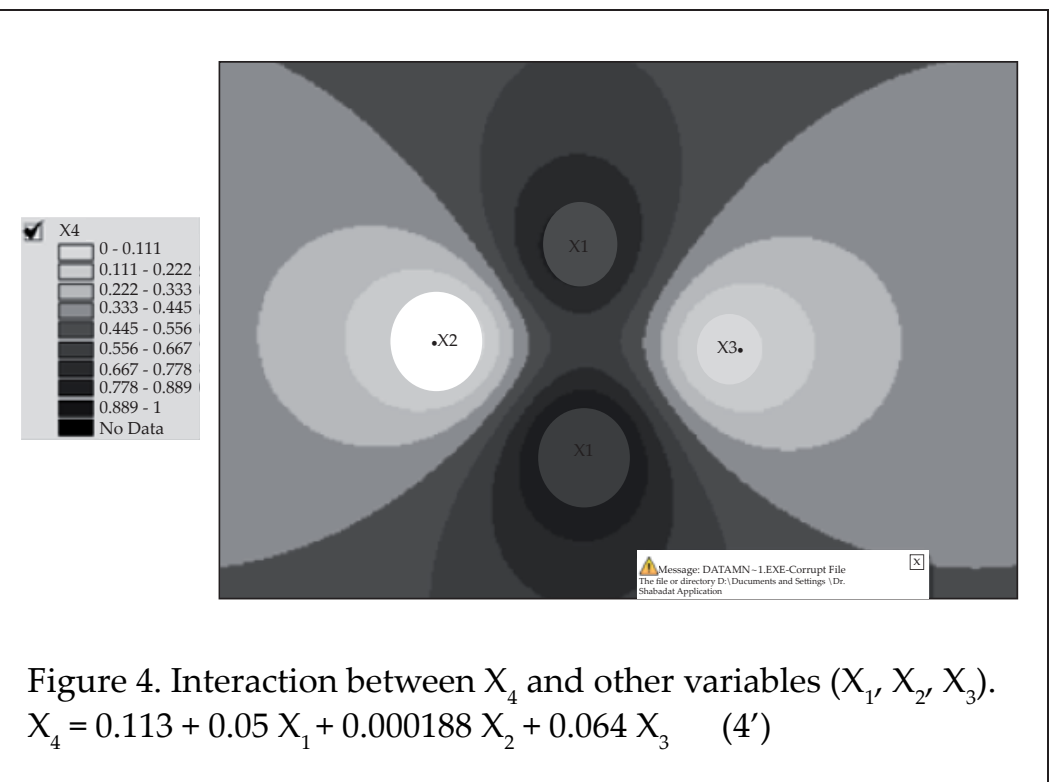




\section{End Notes}

1 (\%share of Oil and Gas) $/(\%$ share of Non-Oil and Gas $)=$ ' $a$ ' is somewhat declining on a trend over the years 2000-2010. This implies, [(GDP Oil and Gas)/Total Economic Activity)]/[(GDP Non-Oil Sector)/(Total Economic Activity $)]=($ GDP Oil and Gas)/(GDP Non-Oil Sector $)[$ Nominal and Real] $=$ ' $a$ ', and is somewhat declining on a trend over the years 2000-2010. Table 1 establishes this fact. The nominal values of ' $a$ ' indicate a maintenance of complementarities between the Oil/Gas and Non-Oil sectors.

2 The neoclassical idea of substitution can work only if the resources of development are assumed to be constrained by a loss of endogenous technological and creative effects. Endogenous effects are by their very nature of the feedback type on cause and effect circularity. Through such a process of circular learning between integrating inputs and outputs, resources, are continuously regenerated by the inherent sharing of complementary potentiality. Consequently, resources continuously augment, and substitution, but not differential levels of allocation of resources are annulled. Scarcity of resources fails to exist by the force of learning as endogenous effect in inter-sectoral participatory development. Thereby, the neoclassical postulate of the marginal rate of substitution cannot exist. By a formalism, let the resource function be denoted by $\mathrm{R}(\mathrm{q})$ $=\mathrm{R}(\mathrm{q}, \mathbf{x}(\mathrm{q}))$. Here the impact of $\mathrm{q}$ on the vector $\mathbf{x}($.$) is denoted by \mathbf{x}(\mathrm{q}) \cdot \mathrm{q}$ denotes inducing knowledge that endogenously regenerates reproducible complementary linkages between the elements of the $\mathbf{x}(\mathrm{q})$-vector.

$3 \mathrm{dR} / \mathrm{dq}=\mathrm{S}_{\mathrm{i}}\left(\mathbb{T} R / \mathbb{I} \mathrm{x}_{\mathrm{i}}\right) \cdot(\mathrm{dx} / \mathrm{dq})>0$ identically under the endogenous augmenting effect of $q$ on both $x_{i}$ and $R$ when complementariies between the $x_{i}-$ vector exist. The term, $\left(\mathbb{I} R / \mathbb{I}\left[x_{i}\right)>0\right.$ denotes the resource augmenting effect of complementarities between $\mathrm{x}_{\mathrm{i}}$-variables. $(\mathrm{dx} / \mathrm{dq})>0$ denotes the endogenous technological effect of $q$ on $x_{i}$. Because these effects are uniform over all $\mathrm{x}_{\mathrm{i}}$-variables, endogeneity and complementary are simultaneous.

4 But the following is possible: $\mathrm{d}^{2} \mathrm{R} / \mathrm{dq}^{2}$ can assume all possible signs. This means that with condition $(1),(\mathrm{d} / \mathrm{dq})(\mathrm{dR} / \mathrm{dq})=(\mathrm{d} / \mathrm{dq})\left[\mathrm{S}_{\mathrm{i}}\left(\mathbb{I} \mathrm{R} / \mathbb{I} \mathrm{I}_{\mathrm{i}}\right) \cdot(\mathrm{dx} / \mathrm{dq})\right]$ $=\left[\mathrm{S}_{\mathrm{i}}\left\{\left(\mathbb{I R} / \mathbb{I} \mathrm{x}_{\mathrm{i}}\right) \cdot\left(\mathrm{d} 2 \mathrm{x}_{\mathrm{i}} / \mathrm{dq}^{2}\right)+(\mathrm{dx} / \mathrm{dq}) \cdot\left(\mathrm{d}^{2} \mathrm{R} / \mathrm{dqdx}_{\mathrm{i}}\right)\right]\right.$ can assume all possible signs. This result implies that although there pervade complementarities between the variables the degree of such complementarities can vary along the growth path of resource allocation.

5 When the result (2) is zero it means maximization of resources allocation. Such is the condition underlying allocation of scarce resource to satisfy competing ends between the $x_{i}$-variables. The effect of $q$ fades away. $\mathrm{R}(\mathrm{q})$ and $\mathbf{x}(\mathrm{q})$ become independent of $\mathrm{q}$. Thereby, the marginal rate of substitution between $x_{i}$-variables returns. This is the cause and effect of the disappearance of the learning feedback condition in the neoclassical problem of optimal allocation of resources between the competing ends of $\mathrm{x}_{\mathrm{i}}$-variables.

6 When the coefficient value between the independent $\left(x_{i}\right)$ and the dependent $\left(\mathrm{x}_{\mathrm{i}}\right)$ relationship is negative, this means, $d \mathrm{x}_{\mathrm{i}} / \mathrm{dx}_{\mathrm{j}}<0$, implying 
marginal rate of substitution between the variables, and thus the absence of complementarities between them. Such instances are subject to simulation of the coefficients to turn them into the desired degrees of complementarities or decreased marginal rate of substitution.

\section{References}

Bertuglia, C. S., \& Vaio, F. (2005). Nonlinear models in social processes: The model of Volterra-Lotka and some of its variants in ecology. In Nonlinearity, chaos $\mathcal{E}$ complexity, the dynamics of natural and social systems (pp. 93-107). Oxford, UK: Oxford University Press.

Central Bank of Oman. (2013). Annual Report 2012. Muscat, Oman.

Choudhury, M. A. (2009). Dialectics in socio-scientific inquiry: Islam contra occident. International Journal of Sociology and Social Policy, 29, 9-10.

Choudhury, M. A., \& Hossain, M. S. (2006). Development planning in the Sultanate of Oman. New York: Edwin Mellen Press.

Choudhury, M. A., \& Al-Sahlawi, M. (2000, September 3). Oil and non-oil sectors in Saudi Arabia. OPEC Review, XXIV.

Choudhury, M. A., Hossain, M. Z., \& Hossain, M. S. (2011). Estimating an ethical index of human wellbeing. Journal of Developing Areas, 45(1), 375-409.

Fitzpatrick, T. (2003). Postmodernism and new directions. In P. Alcock, A. Erskine \& M. May (Eds.), Social policy (pp. 125-133). Oxford, England: Blackwell.

Jackson, E. T., \& Kassam, Y. (Eds.) (1998). Knowledge shared, participatory evaluation in development cooperation. West Hartford, CONN: Kumarian Press.

Liebenstein, H. (1966). Allocation efficiency vs. x-Efficiency. American Economic Review, 56(Issue 3), 392-415.

Myrdal, G. (1958). The principle of cumulation. In P. Streeten (Ed.), Value in social theory, a selection of essays on methodology by Gunnar Myrdal (pp. 198-205), New York: Harper \& Brothers.

North, D. C. (1981). A theory of institutional change and the economic history of the Western World. In his Structure and change in economic history [Chapter15]. New York: W.W. Norton.

Popper, K. (1998). Conjectures and refutations: The growth of scientific knowledge. London: Routledge \& Kegan Paul.

Romer, P. M. (1986). Increasing returns and long-run growth. Journal of Political Economy, 94, 1002-1037. 
Shakun, M. F. (1988). Evolutionary systems design, policy making under complexity and group decision support systems. Oakland, CA: Holden-Day.

Taleb, N. N. (2007). The black swan: The impact of the highly improbable. New York: Random House.

Simon, H. (1957). Models of man. New York: John Wiley \& Sons.

Simon, H. A. (1960). Decision-making and organizational design. In D. S. Pugh (Ed.), Organization theory (pp. 202-223). Hammondsworth, Middlesex, Eng: Penguin Books.

Soros, G. (2000). Reflexivity in financial markets. Reflexivity in history. In Open society (pp. 59-90). New York: Public Affairs.

Toner, P. (1999). Gunnar Myrdal (1898-1987): Circular and cumulative causation as the methodology of the social sciences. In Main currents in cumulative causation, the dynamics of growth and development [Chapter 5]. Houndmills, Hampshire: Macmillan Press.

Tordo, S., Warner, M., Monzano, O. E., \& Anouti, Y. (2013). Local content policies in the oil and gas sector. World Bank Study. Washington D.C: World Bank. 